\title{
BMJ Open Trends in resource use and effectiveness of ultrasound detection of fetal structural anomalies in France: a multiple registry-based study
}

\author{
Clément Ferrier, ${ }^{1}$ Ferdinand Dhombres, ${ }^{1}$ Babak Khoshnood, ${ }^{2,3}$ \\ Hanitra Randrianaivo, ${ }^{4}$ Isabelle Perthus, ${ }^{5}$ Lucie Guilbaut, ${ }^{1}$ \\ Isabelle Durand-Zaleski, ${ }^{6,7}$ Jean-Marie Jouannic ${ }^{1}$
}

To cite: Ferrier C, Dhombres F, Khoshnood B, et al. Trends in resource use and effectiveness of ultrasound detection of fetal structural anomalies in France: a multiple registrybased study. BMJ Open 2019;9:e025482. doi:10.1136/ bmjopen-2018-025482

- Prepublication history for this paper is available online. To view these files, please visit the journal online (http://dx.doi org/10.1136/bmjopen-2018025482).

Received 19 July 2018 Revised 22 November 2018 Accepted 23 November 2018

Check for updates

(c) Author(s) (or their employer(s)) 2019. Re-use permitted under CC BY-NC. No commercial re-use. See rights and permissions. Published by BMJ.

For numbered affiliations see end of article.

Correspondence to Dr Isabelle Durand-Zaleski; isabelle.durand-zaleski@aphp.fr

\section{ABSTRACT}

Objective To analyse trends in the number of ultrasound examinations in relation to the effectiveness of prenatal detection of birth defects using population-based data in France.

Design A multiple registry-based study of time trends in resource use (number of ultrasounds) and effectiveness (proportion of cases prenatally diagnosed).

Setting Three registries of congenital anomalies and claims data on ultrasounds for all pregnant women in France.

Participants There were two samples of pregnant women. Effectiveness was assessed using data from three French birth defect registries. Resource use for ultrasound screening was based on the French national healthcare database.

Main outcome measures The main outcome measures were prenatal diagnosis (effectiveness) and the average number of ultrasounds (resource use). Statistical analyses included linear and logistic regression models to assess trends in resource use and effectiveness of prenatal testing, respectively.

Results The average number of ultrasound examinations per pregnancy significantly increased over the study period, from 2.47 in 2006 to 2.98 in 2014 ( $p=0.005)$. However, there was no significant increase in the odds of prenatal diagnosis. The probability of prenatal diagnosis was substantially higher for cases associated with a chromosomal anomaly $(91.2 \%)$ than those without (51.8\%). However, there was no evidence of an increase in prenatal detection of either over time.

Conclusions The average number of ultrasound examinations per pregnancy increased over time, whereas the probability of prenatal diagnosis of congenital anomalies did not. Hence, there is a need to implement policies such as high-quality training programmes which can improve the efficiency of ultrasound examinations for prenatal detection of congenital anomalies.

\section{INTRODUCTION}

Congenital abnormalities occur in approximately $2 \%$ of all live births. ${ }^{1}$ They are one of the leading causes of infant mortality
Strengths and limitations of this study

- We observed the chronological trend of the French ultrasound birth defect screening programme.

- We measured the detection rate of birth defects and the number of screening ultrasound per pregnancy.

- We used two large data sources: national registries of birth defect and the national claims database.

- We excluded birth defects detected by other methods.

- There was no linkage between records of patients in the two data sources.

and morbidity in industrialised countries. ${ }^{2-4}$ Prenatal diagnosis of congenital abnormalities is a prerequisite for adequate prenatal counselling and management, and in the case of severe abnormalities without curative option it offers the possibility of termination of pregnancy for fetal abnormality (TOPFA).

In France, prenatal screening for the detection of fetal anomalies is organised by laws and guidelines which apply to both freestanding clinics and public or private hospitals. In addition, all physicians (obstetricians or radiologists) or midwives performing screening ultrasound (US) examinations are certified by a degree obtained after a specific initial training. Three US screening examinations are recommended in singleton pregnancies at 11-14 weeks', 20-25 weeks' and 30-35 weeks' gestation (WG). ${ }^{5}$ Besides these US examinations, a first trimester combined test is offered to each pregnant woman for the evaluation of the risk for Down's syndrome. ${ }^{6}$ When a fetal anomaly is suspected, patients are referred to specialised referral centres for further investigations. ${ }^{7}$ There are 49 referral centres for prenatal diagnosis in France and its territories. The regional implementation of centres is determined by the number of 
births. TOFPA is authorised up to the end of the pregnancy, at the request of the mother, once two experts have certified the severity of the fetal anomaly. ${ }^{8}$

The French national health insurance covers the entire cost of the prenatal screening of fetal anomalies. However, the number of scans performed per pregnancy and its result in terms of prenatal detection rate for fetal anomalies have never, to our knowledge, been studied so far, while representing a significant amount of public resources either in France or in other countries.

Our objective was to assess the effectiveness of US prenatal screening for fetal anomalies by measuring the trend in the number of US examinations for the detection of fetal anomalies and the proportion of anomalies prenatally diagnosed between 2006 and 2014 in France.

\section{DATA AND METHODS}

\section{Data sources and patients}

We used two data sources for our study. In order to identify trends in the average number of US examinations per pregnancy, we used the national claims database: the Système National d'Information Inter-Régimes de l'Assurance Maladie. ${ }^{9}$ Our data source was the Echantillon Généraliste des Bénéficiaires, a permanent representative sample of 1/97 of the individuals covered by the French Health Insurance System. ${ }^{10}$ This representative sample, however, does not allow region-specific analyses.

We used data for all women who had delivered between 2006 and 2014 in France. The claims database identifies each episode of care by a code. Codes used to identify US examinations performed during the pregnancy inform on the indication. We included scans for the detection of fetal anomalies (systematic first, second and third trimester US examinations) or scans for the monitoring of a known fetal anomaly, fetal echocardiography. These scans were performed either in free-standing or in hospital facilities (public or private).

Examinations with no relation to the prenatal detection of fetal anomalies (dating US examinations before 11 WG, US examinations for fetal growth monitoring including Doppler, fetal well-being evaluation) were used to describe the global trend in pregnancy-associated US examinations but excluded from the analysis of US screening for fetal anomalies. Other imaging procedures (MRI or tomodensitometric examination) were excluded. Because US examinations performed in public hospitals between 2006 and 2009 were not recorded, we applied to hospital scans the same rate of increase as observed in private hospitals and free-standing imaging clinics.

As in almost all European countries, there is no national registry of congenital anomalies in France. To assess the trends in the probability of prenatal detection of congenital anomalies, we used data from three French regional registries of birth defects. These public organisations identify cases with congenital anomalies over a predefined area (usually an administrative region). We included three registries-Auvergne, Paris and La Reunion, all members of EUROCAT, the European network for registries of birth defects ${ }^{11}$-and used the standards recommended for this purpose. We included the population of women who gave birth (live birth or fetal loss after 20 WG) or following a TOFPA in the areas covered by these three registries during the study period (2006-2014). We excluded women who were not residents of those areas. A case was defined as a fetus with at least one abnormality whatever the pregnancy outcome was. Fetal anomalies were the ones listed by EUROCAT (which excludes some minor abnormalities with very low medical or aesthetic impact). ${ }^{12}$ In each case, we systematically extracted the time (prenatal or postnatal) of detection and the type of procedure which led to the detection (US examination, first trimester screening for fetal aneuploidy using maternal blood test, invasive procedures). As the aim of our study was to identify the contribution of US examination on detection of fetal anomalies, other modalities leading to a prenatal diagnosis of fetal anomalies, that is, specific Down's syndrome screening, were excluded (estimated risk $\geq 1 / 250$ ). However, cases associated with a nuchal translucency measurement above the 99th centile or a cervical cystic hygroma were included, as they were considered to be the result of the first US examination since a nuchal translucency above 99th centile led to an estimated risk $\geq 1 / 250$ whatever the results of maternal biochemical markers. ${ }^{13-15}$

Pooling the data of the three registries, the overall detection rate was defined as the ratio of the number of cases detected prenatally (positive screening) to the total number of cases per year. The screening was considered positive if the fetal anomaly was suspected by US during the pregnancy regardless of the precise diagnosis after birth. For multiple abnormalities, the screening was considered positive if at least one had been detected prenatally. The detection rate was also calculated in a secondary analysis for the two subgroups of cases with and without chromosomal anomalies.

We used linear regression to analyse trends in resource use (average number of US exams) and logistic regression to analyse trends in the odds of prenatal detection over time. All analyses were conducted using Stata V.14.0.

\section{RESULTS}

\section{Prenatal detection rate of fetal anomalies}

We included 15989 cases of fetal anomalies (average: 1777 per year [range: 1661-1869]) from the registries between 2006 and 2014. These registries covered an average of 54907 annual births (range: 53422-55977), representing $6 \%-7 \%$ of the total number of births in France. The prevalence of birth defects during the study period was $3.2 \%$ and was fairly stable.

Overall, $18 \%$ of the cases were associated with a chromosomal anomaly. The most common chromosomal anomaly was Down's syndrome (54.4\%). In cases not associated with chromosomal anomalies, $82 \%$ were isolated malformations. Outcomes of pregnancies in cases with 
Table 1 Fetal malformation detection rate between 2006 and 2014 by ultrasound screening

\begin{tabular}{|llll}
\hline & $\begin{array}{l}\text { Overall } \\
\text { detection } \\
\text { rate (\%) }\end{array}$ & $\begin{array}{l}\text { Detection rate } \\
\text { for cases without } \\
\text { chromosomal } \\
\text { abnormalities (\%) }\end{array}$ & $\begin{array}{l}\text { Detection rate } \\
\text { for cases with } \\
\text { chromosomal } \\
\text { abnormalities (\%) }\end{array}$ \\
\hline 2006 & 58.2 & 52.2 & 91.3 \\
\hline 2007 & 57.9 & 52.3 & 90.9 \\
\hline 2008 & 58.7 & 52.6 & 93.2 \\
\hline 2009 & 57.2 & 51.9 & 88.4 \\
\hline 2010 & 57.2 & 52.4 & 92.3 \\
\hline 2011 & 57.8 & 53.4 & 90.5 \\
\hline 2012 & 53.9 & 48.2 & 90.2 \\
\hline 2013 & 57.3 & 52.8 & 93.2 \\
\hline 2014 & 55.2 & 50.2 & 90.9 \\
\hline P value & 0.015 & 0.170 & 0.975 \\
\hline
\end{tabular}

$P$ values for $b$-logit tests of the detection rate by year.

isolated malformations were a live birth in $88.1 \%$, a TOPFA in $10.8 \%$ and a fetal loss in $1.1 \%$ of cases. TOPFA and fetal loss were more frequent in cases with multiple malformations (33.1\% and $3.1 \%$, respectively). For cases with chromosomal anomalies, pregnancy outcomes were live birth in $20.5 \%$, TOPFA in $77.1 \%$ and fetal loss in $2.4 \%$. Of the cases, $1062(6.7 \%)$ were excluded from the calculation of the detection rate because they were related to other modalities of detection than US (mostly the first trimester combined test, less frequently another biological test or a systematic invasive test).

The overall prenatal detection rate (including cases with and without chromosomal anomalies) of US screening in the study period was $57.0 \%$, ranging from $53.9 \%$ to $58.7 \%$ (table 1 ). Consequently, $43 \%$ of cases were detected postnatally. The detection rate was substantially higher for cases associated with chromosomal anomalies, with a mean value of $91.2 \%$ (range: $88.4 \%-93.2 \%$ ). The detection rate for cases without chromosomal anomalies ranged from $48.2 \%$ to $53.4 \%$, and was higher in

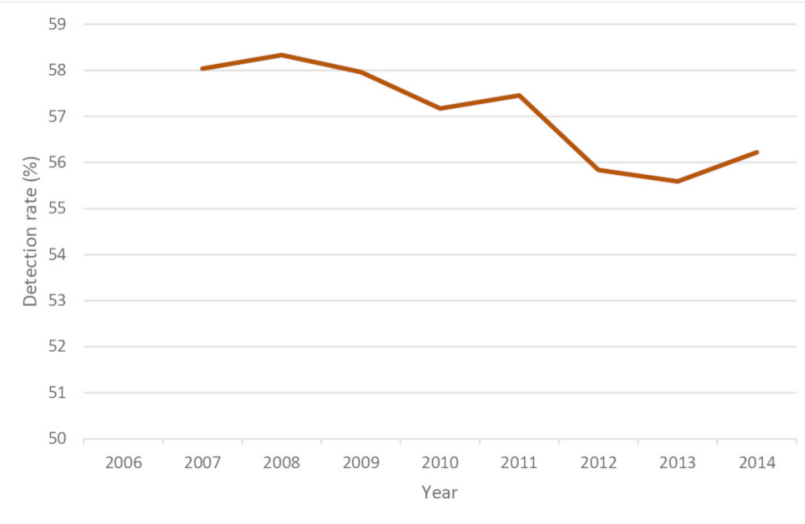

Figure 1 Evolution of the overall ultrasound prenatal detection rate of birth defects during the study period using moving averages (2-year period). cases of multiple anomalies $(70.4 \%)$ than in cases with an isolated anomaly $(47.8 \%)$. The logistic regression found a decreasing trend for the overall prenatal detection rate during the study period ( $\mathrm{OR}=0.985,95 \%$ CI 0.972 to $0.997, \mathrm{p}=0.015)$. Figure 1 represents this trend using moving averages (2-year period).

Resources leveraged for the US screening for fetal anomalies In the $1 / 97$ sample of the national claims database, we identified between 5888 and 6882 deliveries per year $(0.7 \%-0.8 \%$ of the total national number of deliveries). The mean maternal age in our sample was similar to the age observed in the national database (source: INSEE $^{16}$ ). In 2014, an average of 4.08 US examinations were performed per pregnancy, for screening and other indications, compared with 3.78 in 2010 . Table 2 shows the trend in the number of US examinations for the screening of fetal anomalies per pregnancy only. Between 2006 and 2014, we found an increase from 2.47 to 2.98 per pregnancy $(+20.6 \% ; p=0.005)$. We observed an increase of all types of US examinations, especially for the surveillance of fetal anomalies, which went up almost threefold during this period. The number of US examinations unrelated to the screening of fetal anomalies increased from 0.90 to 1.10 per pregnancy between 2010 and 2014, with an increase of $18 \%$ for dating US and of $26 \%$ of US examinations performed for fetal growth surveillance. The average number of invasive procedures related to US screening was stable during the study period, with an incidence of 0.015 per pregnancy.

We analysed the trends for the three subgroups defined by the number of scans performed per pregnancy: $\geq 4$, 3 or $\leq 2$. The trend in each subgroup is presented in figure 2 . The percentage of women with $\geq 4$ US examinations increased between 2010 and $2014(+4.6 \%)$, while those monitored according to the guidelines, that is, three US examinations, decreased by $6 \%$. Moreover, the proportion of women with fewer than three examinations than recommended by the guidelines remained stable.

\section{DISCUSSION}

Using population-based data in France, we found that the average number of US examinations for the detection of fetal anomalies increased over the period between 2006 and 2014, whereas the proportion of cases that were prenatally detected did not. The average number of scans increased from 2.47 to 2.98 per pregnancy during the study period, whereas the overall proportion of fetal anomalies detected prenatally was approximately $60 \%$ and remained essentially stable over time. These results suggest that the increase in the use of resources for prenatal detection of congenital anomalies by US did not match the increase in the proportion of congenital anomalies that were prenatally detected by US.

Our findings do not preclude that the proportion of cases that were prenatally diagnosed for some specific anomalies might have increased over time. However, 
Table 2 Number of screening ultrasound examinations per pregnancy between 2006 and 2014

\begin{tabular}{lllllllllll}
\hline Procedures & $\mathbf{2 0 0 6}$ & $\mathbf{2 0 0 7}$ & $\mathbf{2 0 0 8}$ & $\mathbf{2 0 0 9}$ & $\mathbf{2 0 1 0}$ & $\mathbf{2 0 1 1}$ & $\mathbf{2 0 1 2}$ & $\mathbf{2 0 1 3}$ & $\mathbf{2 0 1 4}$ & P value \\
\hline T1 ultrasound & 0.73 & 0.79 & 0.92 & 0.88 & 0.89 & 0.89 & 0.87 & 0.88 & 0.88 & 0.102 \\
T2 ultrasound & 0.84 & 0.80 & 0.96 & 0.92 & 0.94 & 0.95 & 0.94 & 0.95 & 0.95 & 0.033 \\
T3 ultrasound & 0.82 & 0.74 & 0.89 & 0.85 & 0.88 & 0.87 & 0.87 & 0.89 & 0.87 & 0.102 \\
Surveillance & 0.07 & 0.11 & 0.11 & 0.13 & 0.14 & 0.17 & 0.18 & 0.24 & 0.26 & 0.003 \\
Fetal heart & 0.01 & 0.02 & 0.01 & 0.02 & 0.02 & 0.02 & 0.02 & 0.02 & 0.03 & $<0.001$ \\
Total & 2.47 & 2.45 & 2.89 & 2.79 & 2.87 & 2.90 & 2.89 & 2.98 & 2.98 & 0.005 \\
\hline
\end{tabular}

$P$ values for simple linear regression of the number of procedures per pregnancy by year.

$\mathrm{T} 1$, first trimester; T2, second trimester; T3, third trimester.

given the essentially constant overall proportion of cases that were prenatally diagnosed, any such improvements must have been restricted to a limited number of anomalies and would have been relatively small in magnitude.

The $60 \%$ detection rate pertained to US only. Consequently, cases detected by other modalities were not taken into account (mostly the first trimester combined test with nuchal translucency (NT) $<99$ th), representing an additional $7 \%$ of cases each year. Therefore, the global detection rate including all modalities of prenatal detection is expected to be slightly higher. US screening is highly effective in detecting malformations associated with chromosomal anomalies, with an average detection rate of $90.8 \%$. Two-thirds of these cases were detected at first trimester US examination. This is of importance because in these cases most of the patients opt for TOPFA, which in return reduces the maternal morbidity when performed in the earlier stage of pregnancy.

The stability of the detection rate of fetal anomalies that we observed contrasts with the continuous increase $(+20.6 \%)$ of the number of US examinations performed between 2006 and 2014. This increase did not benefit all women. Indeed, it occurred almost only in the subgroup

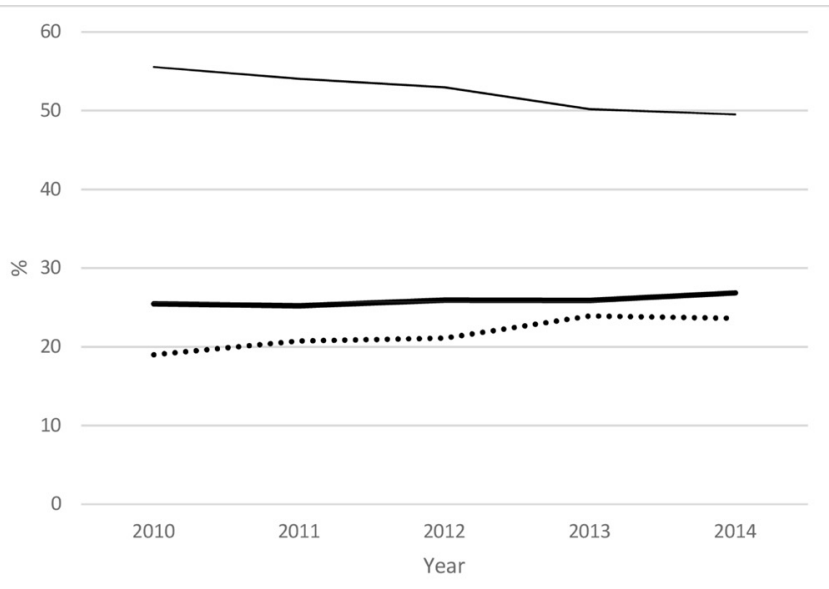

Figure 2 Proportion of screening ultrasound examinations performed during pregnancy in three subgroups: group $A$, three ultrasound examinations (thin line); group B, two or less ultrasound examinations (bold line); and group C, four or more ultrasound examinations (dotted line). of women benefiting from four or more US examinations per pregnancy. This observation corresponds with the results of the French National Perinatal Survey, which reported an increase in the average number of US examinations performed per pregnancy from 4.0 in 1995 to 5.0 in 2010 and 5.5 in $2016(+10 \%) .{ }^{17}$ Similarly, we observed an increase of $8.2 \%$ between 2010 and 2014, considering all categories of US examinations. Additionally, in the French National Perinatal Survey, the proportion of women on whom more than six US examinations were performed during their pregnancy increased from 15.8\% in 1995 to $35.9 \%$ in 2016. In parallel, the proportion of pregnant women with three US examinations decreased from $40.4 \%$ in 2003 to $24.3 \%$ in 2016 . This survey is based on self-reported data, which makes it almost impossible to know what kind of US examination was performed. In our study, the database only contained codes used by care providers to record US examinations, and no other clinical information or the precise indications for these examinations.

Previous studies have reported the trends in the prenatal detection rate of fetal anomalies with slightly different detection rates on specific abnormalities among European regions enrolled in the EUROCAT network. ${ }^{18-24}$ One of our strengths is that we combined data from different registries to estimate the global prenatal detection rate in France. Additionally, our study focused on the contribution of US alone, whereas other studies usually include all the modalities of detection of fetal anomalies, which makes it difficult to identify the contribution of US as the specific screening for aneuploidies is in constant evolution (from sequential to combined test, to non-invasive testing using cell-free DNA in the maternal plasma).

Our study had limitations and caveats. One is related to the lack of exact correspondence between the study population used for identifying trends in resource use (number of US examinations) versus the study population for assessing trends in the effectiveness of prenatal detection (proportion of cases prenatally detected). It is possible that the trends in resource use might be different for the subsample of the French population that resided in the catchment areas of the three registries. However, we have neither a priori reasons nor empirical evidence to suggest that this should be the 
case. Moreover, the prenatal diagnosis practices and policies are mainly decided at the national level. Hence, we do not believe that this lack of exact correspondence between our study populations for assessing trends in resource use versus effectiveness could have biased our results in one way or another.

Due to a modification in the calculation of the hospital's funding between 2006 and 2009, the number of US examinations performed during this period in public hospitals was not recorded and had to be estimated. However, we have no reason to think there were differences between private and public providers during this period. In addition, public hospitals account for less than $20 \%$ of US examinations, thus limiting a potential bias resulting from the estimation we have made for this period.

The development of US screening and its widespread use in France during the 1980s led to a significant improvement in the prenatal detection rate of fetal anomalies. However, stagnation was observed from 2000s. ${ }^{25}$ Our results confirm that stagnation in the detection rate. In parallel, we observed a significant increase in the number of US examinations performed. In addition, we observed that this increase did not benefit all women. Conversely, the increase was even more pronounced in the subgroup of women receiving more than recommended. The ecological design of our study limits the interpretation of the observed trends. However, the trend indicated a further increase in inequality of care for the surveillance of pregnant women. Although these results cannot be easily mapped to other countries, this study should stimulate similar analyses in other countries where a systematic screening of fetal anomalies using US is organised.

\section{CONCLUSIONS}

Our study has shown that even though the number of US examinations per pregnancy increased over time, the prenatal detection rate of fetal anomalies has not increased in recent years. These data suggest that there is a need to implement policies to improve the efficacy of US examination for prenatal diagnosis of congenital anomalies, including more high-quality training programmes.

\section{Author affiliations}

${ }^{1}$ Fetal Medicine Department, Sorbonne University, AP-HP, Armand Trousseau Hospital, Paris, France

${ }^{2}$ INSERM U1142, LIMICS, Sorbonne University, Paris, France

${ }^{3}$ Paris registry of congenital anomalies, Port-Royal Hospital, Paris, France

${ }^{4}$ Reunion registry of congenital anomalies, St Pierre, Saint Pierre de la Réunion, France

${ }^{5}$ Study center for congenital anomalies, CEMC-Auvergne, Clermont-Ferrand, France ${ }^{6}$ INSERM CRESS UMR 1153, Paris, France

${ }^{7}$ AP-HP, URCEco lle de France, Hôtel-Dieu Hospital, Paris, France

Acknowledgements The authors express their gratitude to the team of the birth defect registers that participated in the study.

Contributors All authors listed on this manuscript fulfil the ICMJE criteria.CF, $\mathrm{BK}, \mathrm{J}-\mathrm{MJ}$ and ID-Z conceptualised the study and designed the analysis. FD was certified for EGB database access. CF, FD, BK, LG, HR and IP collected the data. All authors contributed to the analysis. CF, FD, BK, J-MJ, LG and ID-Z wrote the final manuscript. J-MJ and ID-Z were the guarantors of the study.

Funding The authors have not declared a specific grant for this research from any funding agency in the public, commercial or not-for-profit sectors.

Competing interests None declared.

Patient consent for publication Not required.

Ethics approval This was a time-trend observation of aggregated data provided by an analysis of anonymised individual data and did not require ethical approval. The EGB analysis, part of the SNIIRAM and property of the CNAMTS, was performed after INSERM approval and is covered by the Commission Nationale de I'Informatique et des Libertés (CNIL) (accords CNIL AT/CPZ/SVT/JB/DP/CR052220 du 14/06/2005 et DP/CR071761 du 28/08/2007).

Provenance and peer review Not commissioned; externally peer reviewed. Data sharing statement There are no unpublished data.

Open access This is an open access article distributed in accordance with the Creative Commons Attribution Non Commercial (CC BY-NC 4.0) license, which permits others to distribute, remix, adapt, build upon this work non-commercially, and license their derivative works on different terms, provided the original work is properly cited, appropriate credit is given, any changes made indicated, and the use is non-commercial. See: http://creativecommons.org/licenses/by-nc/4.0/.

\section{REFERENCES}

1. Centers for Disease Control and Prevention (CDC). Update on overall prevalence of major birth defects--Atlanta, Georgia, 1978-2005. MMWR Morb Mortal Wkly Rep 2008;57:1-5.

2. Lee K, Khoshnood B, Chen L, et al. Infant mortality from congenital malformations in the United States, 1970-1997. Obstet Gynecol 2001;98:620-7.

3. Hatton F, Bouvier-Colle MH, Blondel B, et al. [Trends in infant mortality in France: frequency and causes from 1950 to 1997]. Arch Pediatr 2000;7:489-500.

4. Matthews TJ, MacDorman MF, Thoma ME. Infant mortality statistics from the 2013 period linked birth/infant death data set. Natl Vital Stat Rep 2015;64:1-30.

5. Sureau C, Henrion R. Assessment by the national committee for ulstrasound prenatal screening CNTE (Comité National Technique de l'Echographie de dépistage prénatal) report. 2005.

6. French Law: bylaw establishing guidelines for prenatal screening and diagnosis. Legislation: Arrêté du 23 juin 2009 fixant les règles de bonnes pratiques en matière de dépistage et de diagnostic prénatals avec utilisation des marqueurs sériques maternels de la trisomie 21. Source: internet. https://www.legifrance.gouv.fr/affichTexte.do? cidTexte=JORFTEXT000020814373, le 03/09/2017.

7. French Law: law on organ donation, medically assisted procreation and prenatal diagnosisi Legislation. LOI no 94-654 du 29 juillet 1994 relative au don et à l'utilisation des éléments et produits du corps humain, à l'assistance médicale à la procréation et au diagnostic prénatal (1). https://www.legifrance.gouv.fr/affichTexte.do?cidTexte= JORFTEXT000000549618\&categorieLien=id.

8. French Law: law on terminataion of pregnancy for medical reasons Legislation. LOI no 2001-588 du 4 juillet 2001 relative à l'interruption volontaire de grossesse et à la contraception. http://admi.net/jo/ 20010707/MESX0000140L.html le 03/09/2017.

9. Tuppin P, Rudant J, Constantinou P, et al. Value of a national administrative database to guide public decisions: from the système national d'information interrégimes de l'assurance maladie (sniiram) to the système national des données de santé (snds) in france. Rev Epidemiol Sante Publique 2017;65:S149-S167.

10. Bezin J, Duong M, Lassalle R, et al. The national healthcare system claims databases in France, SNIIRAM and EGB: Powerful tools for pharmacoepidemiology. Pharmacoepidemiol Drug Saf 2017;26:954-62.

11. Boyd PA, Haeusler M, Barisic I, et al. Paper 1: The EUROCAT network--organization and processes. Birth Defects Res A Clin Mol Teratol 2011;91:S2-S15.

12. EUROCAT Guide 1.4 Section 3.2. Minor anomalies for exclusion. 2017;11. http://www.eurocat-network.eu/content/Section\%203.2-\% 2027_Oct2016.pdf.

13. Nicolaides $\mathrm{KH}$, Azar G, Byrne D, et al. Fetal nuchal translucency: ultrasound screening for chromosomal defects in first trimester of pregnancy. BMJ 1992;304:867-9.

14. Taipale P, Hiilesmaa V, Salonen R, et al. Increased nuchal translucency as a marker for fetal chromosomal defects. $N$ Engl J Med 1997;337:1654-8. 
15. Snijders RJ, Noble P, Sebire N, et al. UK multicentre project on assessment of risk of trisomy 21 by maternal age and fetal nuchaltranslucency thickness at 10-14 weeks of gestation. fetal medicine foundation first trimester screening group. Lancet 1998;352:343-6.

16. INSEE. Âge moyen de la mère à l'accouchement en 2017. 2017;11. https://www.insee.fr/fr/statistiques/2381390\#tableau-Donnes.

17. Blondel $\mathrm{B}$, Coulm B, Bonnet $\mathrm{C}$, et al. Trends in perinatal health in metropolitan France from 1995 to 2016: Results from the French National Perinatal Surveys. J Gynecol Obstet Hum Reprod 2017:46:701-13

18. Garne $\mathrm{E}$, Loane $\mathrm{M}$, Dolk $\mathrm{H}$, et al. Prenatal diagnosis of severe structural congenital malformations in Europe. Ultrasound Obstet Gynecol 2005;25:6-11.

19. Garne E, Loane M, Wellesley D, et al. Congenital hydronephrosis: prenatal diagnosis and epidemiology in Europe. J Pediatr Urol 2009;5:47-52.

20. Boyd PA, Devigan C, Khoshnood B, et al. Survey of prenatal screening policies in europe for structural malformations and chromosome anomalies, and their impact on detection and termination rates for neural tube defects and down's syndrome. BJOG 2008;115:689-96.

21. Pedersen RN, Calzolari E, Husby S, et al. Oesophageal atresia: prevalence, prenatal diagnosis and associated anomalies in 23 European regions. Arch Dis Child 2012;97:227-32.

22. Garne E. Prenatal diagnosis of six major cardiac malformations in Europe--a population based study. Acta Obstet Gynecol Scand 2001;80:224-8.

23. Boyd PA, Loane M, Garne E, et al. Sex chromosome trisomies in Europe: prevalence, prenatal detection and outcome of pregnancy. Eur J Hum Genet 2011;19:231-4.

24. Khoshnood B, De Vigan C, Vodovar V, et al. A population-based evaluation of the impact of antenatal screening for down's syndrome in France, 1981-2000. BJOG 2004;111:485-90.

25. Khoshnood B, Lelong N, Lecourbe A, et al. Registre des Malformations Congénitales de Paris (registre qualifié 2013-2016 2014. 